\title{
Comparison of clinical and cytological findings in the diagnosis of vulvovaginitis in adult women
}

\author{
Celeste Maria de Menezes Souza ${ }^{1}$, Hugo Marcus Rodrigues ${ }^{2}$, Márcia Guimarães da Silva ${ }^{3}$, Camila Marconi ${ }^{4}$, Ricardo Ney Oliveira Cobucci ${ }^{5 *}$ \\ and Ana Katherine Gonçalves ${ }^{1}$
}

${ }^{1}$ Gynecology and Obstetric Department, Universidade Federal do Rio Grande do Norte - UFRN, Natal, Brazil

${ }^{2}$ Health Science Post Graduate Program, Universidade Federal do Rio Grande do Norte - UFRN, Natal, Brazil

${ }^{3}$ Pathology Department, Universidade Estadual Paulista- UNESP,São Paulo, Brazil

${ }^{4}$ Pathology Department, Universidade Estadual Paulista- UNESP,São Paulo, Brazil

${ }^{5}$ Gynecology and Obstetric Department, Universidade Potiguar - UnP, Natal, Brazil

\begin{abstract}
Background: Inability to diagnose vulvovaginal infections is a growing concern. Specialist knowledge of how to prepare and assess wet mount slides for the diagnosis of vulvovaginitis is the exception.

Aim: This study evaluated 200 women who complained about vaginal discharge to determine the accuracy of the methods available for the diagnosis of vulvovaginitis.

Materials and methods: Vaginal smear was collected for microbiological tests (Pap smear, wet mount and Gram stain); the gram stain method was the gold standard. The clinical diagnosis was based on signs and symptoms. The efficacy of the available methods for diagnosis of vaginal discharge was assessed: sensitivity (S), specificity (SP), positive predictive value (PPV) and negative predictive value (NPV).

Results: Concerning Wet mount: Vaginal candidiasis (VC): S=31\%; SP=97\%; PPV=54\%; NPV =93\%; accuracy=91\%. Bacterial vaginosis (BV): S=80\%; SP =95\%; $\mathrm{PPV}=80 \%$; NPV=95\%; accuracy=92\%. Regarding Syndromic approach: BV: S=95\%; SP=43\%; PPV=30\%; NPV=97\%; accuracy=54\%. VC: S=75\%; SP =91\%; $\mathrm{PPV}=26 \%$; NPV=98\%; accuracy=90\%. Pap smear for VC: $\mathrm{S}=68 \%, \mathrm{SP}=98 \%$; PPV=86\%; NPV =96\%; accuracy=96\%. BV: S=75\%; SP=100\%; PPV=100\%; NPV =94\%; accuracy $=95 \%$. There was only one case of vaginal trichomoniasis.
\end{abstract}

Conclusion: Pap smear and wet mount showed respectively low and very low sensitivity for VC. The syndromic approach showed very low specificity and accuracy for BV.

\section{Introduction}

Despite its tremendous practical importance, infectious diseases training in gynecology still leaves much to be desired [1,2]. Attempts to detect the underlying causes of symptoms may be carried out on a "trial and error" basis, resulting in unnecessary or inadequate microbiologic diagnostic investigations and antibiotic treatment which may not be suitable or may be insufficient or in the worst case, have adverse consequences for patients [2].

Ultimately, a correct diagnosis is not yielded. Inability to diagnose vulvovaginal infections is a growing concern. For various reasons, specialist knowledge of how to prepare and assess wet mount slides for microscopic investigation of vaginal discharge is the exception rather than the rule in outpatient clinics or hospitals [3-5]. In contrast to developed countries where regulations require wet mount proficiency testing, gynecologists in Brazil do not currently need to prove their specialist knowledge in this area. This is an extremely welcome development, not least because the overwhelming number of uncomplicated vulvovaginal symptoms can already be diagnosed using basic diagnostic procedures; whereas the diagnosis of vulvovaginitis can usually be fairly straightforward based on the patient'smedical history, clinical examination with measurement of vaginal $\mathrm{pH}$, whiff test and evaluation of wet mount slides [1,2]. The latter methods are usually also sufficient to differentiate between normal vaginal findings and vulvovaginitis with a relatively high degree of accuracy [1].

The emphasis of this article is on basic diagnostic procedures that can be carried in the practice of a registered doctor or hospital at limited cost. The purpose of the present study was to compare the current clinical and cytological diagnosis approaches on women with vulvovaginal discharge complaint.

\section{Materials and methods}

This study was conducted at a gynecology outpatient clinic between March 2014 and March 2015. The study protocol was approved by the Local Ethics Committee (CAAE=17911813.4.0000.5292). All premenopausal women applying to our gynecology outpatient clinic with the vaginal discharge complaint were enrolled prospectively into the study after written informed consent was obtained. Exclusion

Correspondence to: Ricardo Ney Oliveira Cobucci, Gynecology and Obstetric Department, Universidade Potiguar - UnP, Natal, Brazil, Tel: +558420209051; E-mail: drcobucci@gmail.com

Key words: diagnosis, candidiasis, bacterial vaginosis, trichomoniasis

Received: May 29, 2016; Accepted: July 04, 2016; Published: July 08, 2016 
criteria were the presence of vaginal bleeding, pregnancy, intercourse in the last 24 hours and the use of antibiotic or immunosuppressive drugs in the last month.

Each patient underwent an evaluation that included a standardized history with information about present genital symptoms, pregnancy history, and prior vaginitis history, previous medical history of diabetes mellitus, contraceptive status, and vaginal douching practice. The same physician examined all the patients and results were recorded on a standard form. Each woman underwent speculum examination for direct observation and evaluation of vaginal secretions.

The clinical diagnosis was based on signs and symptoms. Vaginal smear was collected for microbiological tests (Pap smear, wet mount and Gram stain), the gram stain method being considered as the gold standard. The efficacy of the available methods for diagnosis of vaginal discharge was assessed (sensitivity, specificity, positive predictive value and negative predictive value).

The diagnosis of yeast infection was done by the presence of either typical discharge and itching or direct observation of yeast buds or hyphae on the wet mount and Gram stain (Figure 1A and 1B). The diagnosis of Trichomonas infection was done through the observation of motile Trichomonas on the wet mount or typical grayish vaginal discharge. The diagnosis of bacterial vaginosis was possible when the presence of three or more of the following criteria could be observed: homogeneous discharge, vaginal $\mathrm{pH} 4.5$, positive whiff test and identification of clue cells on the wet mount and Gram stain (Figure 1C and 1D).

Data were inserted into a database and analyzed with Graph Pad Prism 6 statistical software. The clinical results were compared to the lab ones to confirm the diagnosis. Diagnostic accuracy was measured with sensitivity, specificity, positive and negative predictive values and accuracy itself.

\section{Results}

Two-hundred patients with vaginal discharge complaint were included in the study. The average age of the participants was 34.5 (16-50). Other complaints accompanying vaginal discharge were bad smell (41.2\%) and itching (46.1\%). Sixty-four individuals (32\%) had a history of previous vaginal infection. There was only one case of vaginal trichomoniasis, diagnosed by cytology and fresh wet mount, confirmed by Gram. The syndromic approach diagnosed it as bacterial vaginosis. (Table 1).

Regarding the effectiveness of diagnostic methods used in this

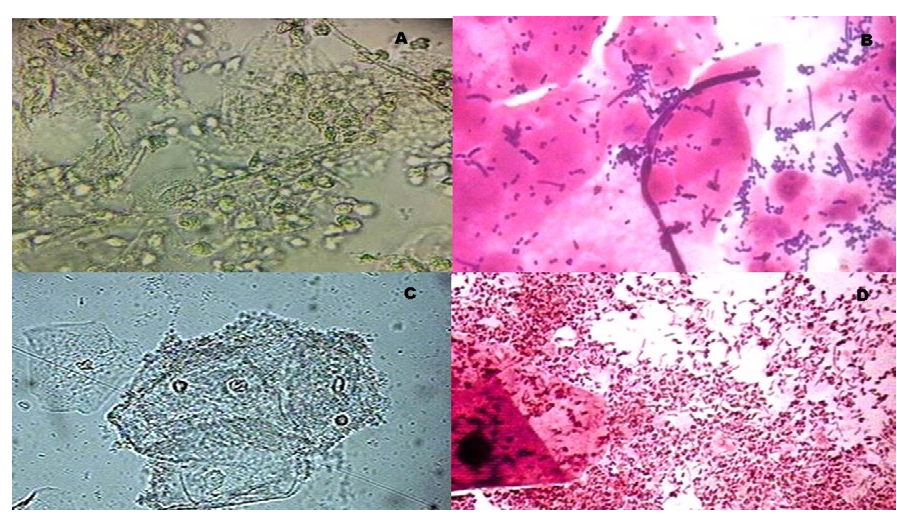

Figure 1: (A) Wet mount of yeast infection, (B) Gram stain of yeast infection, (C) Wet mount of bacterial vaginosis, (D) Gram stain of bacterial vaginosis.
Table 1. Distribution of clinical diagnosis and microbiological results.

\begin{tabular}{|l|c|c|c|c|c|}
\hline Clinical Diagnosis & \multicolumn{5}{|c|}{ Microbiological diagnosis } \\
\cline { 2 - 6 } & $\begin{array}{c}\text { Normal } \\
\text { Flora }\end{array}$ & $\begin{array}{c}\text { Candida } \\
\text { species }\end{array}$ & $\begin{array}{c}\text { Gardnerella } \\
\text { vaginalis }\end{array}$ & $\begin{array}{c}\text { Trichomona } \\
\text { vaginalis }\end{array}$ & Total \\
\hline Physiological discharge & 37 & & 2 & & 39 \\
\hline Fungal infection & 11 & 6 & 1 & & 18 \\
\hline Bacterial vaginosis & 7 & & 32 & 1 & 40 \\
\hline Trichomonial infection & & & & 1 & 1 \\
\hline Mixed infection & 1 & & & & 1 \\
\hline Others & 91 & 5 & 5 & & 101 \\
\hline Total & 147 & 11 & 40 & 2 & 200 \\
\hline
\end{tabular}

Table 2. Accuracy of Pap smear, Wet mount and Syndromic approach in the diagnose of Bacterial Vaginose (BV) and Vaginal Candidiasis (VC).

\begin{tabular}{|l|c|c|c|c|c|}
\hline Method & Sensitivity & Specificity & PPV & NPV & Accuracy \\
\hline Pap for BV & $75 \%$ & $100 \%$ & $100 \%$ & $94 \%$ & $95 \%$ \\
\hline Pap for VC & $68 \%$ & $98 \%$ & $86 \%$ & $96 \%$ & $96 \%$ \\
\hline Wet mount for BV & $80 \%$ & $95 \%$ & $80 \%$ & $95 \%$ & $92 \%$ \\
\hline Wet mount for VC & $31 \%$ & $97 \%$ & $54 \%$ & $93 \%$ & $91 \%$ \\
\hline Syndromic approach for BV & $95 \%$ & $43 \%$ & $30 \%$ & $97 \%$ & $54 \%$ \\
\hline Syndromic approach for VC & $75 \%$ & $91 \%$ & $26 \%$ & $98 \%$ & $90 \%$ \\
\hline
\end{tabular}

study, the following results were obtained: Wet mount for vaginal candidiasis: sensitivity $=31 \%$; specificity $=97 \%$; positive predictive value $(\mathrm{PPV})=54 \%$; negative predictive value $(\mathrm{NPV})=93 \%$; accuracy $=91 \%$. Wet mount for bacterial vaginosis: sensitivity $=80 \%$; specificity $=95 \%$; positive predictive value $(\mathrm{PPV})=80 \%$; negative predictive value $(\mathrm{NPV})=95 \%$; accuracy $=92 \%$. Syndromic approach for bacterial vaginosis: sensitivity $=95 \%$; specificity $=43 \%$; positive predictive value $(\mathrm{PPV})=30 \%$; negative predictive value $(\mathrm{NPV})=97 \%$; accuracy $=54 \%$. Syndromic approach for vaginal candidiasis: sensitivity $=75 \%$; specificity $=91 \%$; positive predictive value $(\mathrm{PPV})=26 \%$; negative predictive value $(\mathrm{NPV})=98 \%$; accuracy $=90 \%$. Pap smear for vaginal candidiasis: sensitivity $=68 \%$, specificity $=98 \%$; positive predictive value $(\mathrm{PPV})=86 \%$; negative predictive value $(\mathrm{NPV})=96 \%$; accuracy $=96 \%$. Pap smear for bacterial vaginosis: sensitivity $=75 \%$; specificity $=100 \%$; positive predictive value $(\mathrm{PPV})=100 \%$; negative predictive value $(\mathrm{NPV})$ $=94 \%$; accuracy $=95 \%$ (Table 2$)$.

\section{Discussion}

Failure to diagnose vulvovaginal infections is a rising concern. Physicians do not adequately make an accurate diagnosis based on symptoms and complete inspections. The causative factors of the disease remain unknown in most patients. In our study, we were able to detect a causative microorganism in only $30 \%$ of women with vaginal discharge complaint. It is consistent with other studies reporting that vaginitis could be diagnosed only in $46-66 \%$ of symptomatic women [6]. On the other hand, $76 \%$ of patients received a clinical diagnosis. The high rate of clinical diagnosis points the clinical over-diagnosis tendency. Our results agree with recent studies that concluded that the clinical diagnosis of vaginal infections, based on history and physical examination is inadequate and should be confirmed by microbiological testing as well [6-8]. Genital tract complaints lead invariably to a significant number of women who are clinically misdiagnosed. This diagnostic inaccuracy is also accompanied by a large number of women who are treated and labeled with a presumed infection that, in fact, are not infected with the suspected pathogens. As a result, patients seek medical help with persisting or recurrent symptoms [7]. As a proof of this fact, $32 \%$ of the participants from the group we studied had a history of previous vaginal infection. 
Furthermore, the presence of symptoms associated with vaginitis including odor, itching or discomfort does not necessarily indicate the presence of a disease since evidence suggests that these symptoms can occur in the normal population [9]. Likewise, in our study population, there was a high rate of complaints accompanying vaginal discharge: bad smell in $41.2 \%$, itching in $46.1 \%$ of patients, but none of these symptoms was predictive of laboratory results. Additionally, most women's health care providers do not run tests on patients with vaginal complaints, and many providers that do perform such tests are not well equipped [3]. Many gynecology and family practice offices and clinics do not even carry $\mathrm{pH}$ paper; those offices and hospitals that do have the paper often have the $\mathrm{pH}$ paper that is insensitive in the 3.5-6.0 $\mathrm{pH}$ range. Thus, even under the best circumstances, diagnoses will be missed and, consequently, erroneous treatments will be applied $[10,11]$.

For the reason that microscopic evaluation requires special diagnostic skills that are not available to all practitioners, misjudgment is constant, therapy is frequently empirical, and the relapse rate is high $[12,13]$. Donders suggested two ways to solve this problem: one would be to teach medical students the proper use of the microscope. The other way would be to have tertiary centers for vulvovaginal infections with dedicated specialists with experience and particular interest in the matter [13]. However, the Gram stain must be established as an indispensable tool for diagnosis of vulvovaginitis. Similar previous study, compared to the microbiological test results, Pap smear was not sensitive enough for screening of vaginal infections. Nevertheless, because of its high specificity, it may be adequate diagnostic criteria when it is positive [14].

These findings suggest that clinical diagnosis based on combining symptoms with office-based testing improves diagnostic accuracy, however, is not enough. The most effective approach also incorporates laboratory testing as an adjunct when a diagnosis is in question or treatment is failing.

\section{Competing interest}

The authors declare no competing interest.

\section{References}

1. Frobenius W, Bogdan C (2015) Diagnostic Value of Vaginal Discharge, Wet Mount and Vaginal pH - An Update on the Basics of Gynecologic Infectiology. Geburtshilfe Frauenheilkd 75: 355-366.

2. Mendling W (2012) Gynäkologische Infektionen: Teil 1. Der Gynäkologe 45: 959-975.

3. Landers DV, Wiesenfeld HC, Heine RP, Krohn MA, Hillier SL (2004) Predictive value of the clinical diagnosis of lower genital tract infection in women. Am J Obstet Gynecol 190: $1004-1010$

4. Mashburn J (2012) Vaginal infections update. J Midwifery Womens Health 57: 629634. [Crossref]

5. Ledger WJ, Monif GR (2004) A Growing concern: inability to diagnose vulvovaginal infections correctly. Obstet Gynecol 103: 782-784.

6. Karaca M, Bayram A, Kocoglu ME, Gocmen A, Eksi F (2005) Comparison of clinical diagnosis and microbiological test results in vaginal infections. Clin Exp Obstet Gynecol 32: 172-174.

7. Anderson MR, Klink K, Cohrssen A (2004) Evaluation of vaginal complaints. JAMA 291: 1368-1379. [Crossref]

8. Lowe NK, Neal JL, Ryan-Wenger NA (2009) Accuracy of the clinical diagnosis of vaginitis compared with a DNA probe laboratory standard. Obstet Gynecol 113: 89-95. [Crossref]

9. Karasz A, Anderson M (2003) The vaginitis monologues: women's experiences of vaginal complaints in a primary care setting. Soc Sci Med 56: 1013-1021. [Crossref]

10. Langsford MJ, Dobbs FF, Morrison GM, Dance DA (2001) The effect of introduction of a guideline on the management of vaginal discharge and in particular bacterial vaginosis in primary care. Fam Pract 18: 253-257. [Crossref]

11. Esim Buyukbayrak E, Kars B, Karsidag AY, Karadeniz BI, Kaymaz O, et al. (2010) Diagnosis of vulvovaginitis: comparison of clinical and microbiological diagnosis. Arch Gynecol Obstet 282: 515-519. [Crossref]

12. Schwiertz A, Taras D, Rusch K, Rusch V (2006) Throwing the dice for the diagnosis of vaginal complaints? Ann Clin Microbiol Antimicrob 5: 4. [Crossref]

13. Donders G (2001) We, specialists in vulvovaginitis. Am J Obstet Gynecol 184: 248249. [Crossref]

14. Karani A, De Vuyst H, Luchters S, Othigo J, Mandaliya K, et al. (2007) The Pap smear for detection of bacterial vaginosis. Int J Gynaecol Obstet 98: 20-23. [Crossref]

Copyright: (2016 Souza CMM. This is an open-access article distributed under the terms of the Creative Commons Attribution License, which permits unrestricted use, distribution, and reproduction in any medium, provided the original author and source are credited. 